\title{
Fog deposition to a Tillandsia carpet in the Atacama Desert
}

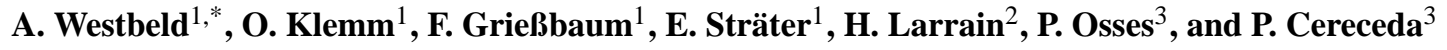 \\ ${ }^{1}$ Institute of Landscape Ecology, Department of Climatology, University of Münster, Münster, Germany \\ ${ }^{2}$ Atacama Desert Center ADC, Pontificia Universidad Católica de Chile and Universidad Bolivariana, Iquique, Chile \\ ${ }^{3}$ Institute of Geography, Pontificia Universidad Católica de Chile, Santiago de Chile, Chile \\ *now at: Institute of Hydrology and Meteorology, TU Dresden, Dresden, Germany
}

Received: 29 March 2009 - Revised: 31 July 2009 - Accepted: 7 September 2009 - Published: 25 September 2009

\begin{abstract}
In the Atacama Desert, one of the driest places on earth, fog deposition plays an important role for the water balance and for the survival of vulnerable ecosystems. The eddy covariance method, previously applied for the quantification of fog deposition to forests in various parts of the world, was used for the first time to measure deposition of fog water to a desert. In this exploratory study we estimate the amount of water available for the ecosystem by deposition and determine the relevant processes driving fog deposition. This is especially important for the species Tillandsia landbecki living in coastal Atacama at the limit of plant existence with fog and dew being the only sources of water. Between 31 July and 19 August 2008 approximately $2.5 \mathrm{~L} \mathrm{~m}^{-2}$ of water were made available through deposition. Wholeyear deposition was estimated as $25 \mathrm{~L} \mathrm{~m}^{-2}$. Turbulent upward fluxes occurred several times during the evenings and are explained by the formation of radiation fog. In connection with that, underestimates of the deposition are assumed. More detailed studies covering various seasons and all parameters and fluxes contributing to the local energy balance are suggested. This will help to further develop understanding about the processes of (i) deposition of water to the desert, and (ii) intensification of advection fog through additional formation of radiation fog.
\end{abstract}

Keywords. Atmospheric composition and structure (Biosphere-atmosphere interactions) - Hydrology (Hydroclimatology) - Meteorology and atmospheric dynamics (Turbulence)



Correspondence to: A. Westbeld (annawestbeld@danek.com)

\section{Introduction}

The western regions of the South American continent comprise some of the driest regions of the world. In the absence of significant rain, highly specialized ecosystems developed that depend on fog as the only source of water. In the semiarid regions (e.g., at $30^{\circ} \mathrm{S}$, Chile), forests exist that largely depend on the deposition of fog water (del-Val et al., 2006). In this study, we focus on the arid region of the Atacama Desert in Northern Chile $\left(20^{\circ} \mathrm{S}\right)$ at Cerro Guanaco, at the coast of the Pacific Ocean.

With $0.8 \mathrm{~mm}$ average annual precipitation during the past 30 years near the study site (Cereceda et al., 2008), the only water resources for plants are fog water and dew. The species Tillandsia landbecki, which forms a monospecific population at the study site, has developed several xeromorphic adaptations such as narrow leaves with water-absorbing trichomes and the ability to use the Crassulacean acid metabolism (CAM) for photosynthetic carbon assimilation to exist exclusively on fog water (Rundel et al., 1997).

The present study has two objectives; 1.) to quantify the amount of water available for the the ecosystem from fog deposition, and 2.) to identify the relevant processes driving fog water deposition.

In previous experiments, the eddy covariance method was proved suitable for the quantification of deposition fluxes of gases, particles, and also fog droplets. It has successfully been applied to fog deposition measurements in North America (Vong and Kowalski, 1995; Kowalski and Vong, 1999), in the Carribean (Eugster et al., 2006; Holwerda et al., 2006), Europe (Beswick et al., 1991; Gallagher et al., 1992; Vermeulen et al., 1997; Thalmann et al., 2002; Burkard et al., 2003; Klemm et al., 2005; Klemm and Wrzesinsky, 2007), and East Asia (Beiderwieden et al., 2007, 2008). All these measurements were carried out over a well-developed plant canopy, whereas the present study is the first one that was done in a desert ecosystem.

Published by Copernicus Publications on behalf of the European Geosciences Union. 


\section{Site and methods}

The investigation area, called Cerro Guanaco, is located in the coastal mountain range of northern Chile at $20^{\circ} 23^{\prime} \mathrm{S}$ and $70^{\circ} 06^{\prime} \mathrm{W}$, about $9 \mathrm{~km}$ from the Pacific Ocean. Due to the location in a typically east/west directed corridor formed between high mountains reaching altitudes up to about $1400 \mathrm{~m}$ a.s.l., advective and orographic fog can penetrate inland far enough to reach the study site at $1100 \mathrm{~m}$ a.s.l. (Cereceda et al., 2007).

According to Köppen's Climate Classification (Peel et al., 2007), the region is a coastal desert with abundant cloudiness (BWn). Over the ocean, the very stable Southeast Pacific subtropical anticyclone persists all year. High pressure is typical for subtropical latitudes such as northern Chile and is caused by large scale subsidence compensating for the ascending air along the intertropical convergence zone (ITCZ). While the air subsides, it warms and dries adiabatically causing a temperature inversion at about $1 \mathrm{~km}$ above the surface. In the marine boundary layer, which is shallow because of the influence of the cold Humboldt Current, little turbulence is generated by convective processes. Therefore, clouds can not penetrate the inversion layer and spread horizontally, creating an extended stratocumulus (Sc) deck (Garreaud et al., 2007) leading to advective fog over the land once the clouds contact the coastal mountains and plains.

While advective fog, called Camanchaca by the local inhabitants, is most frequent, two more kinds of fog occur in the North of Chile: orographic fog and radiation fog. The term orographic fog corresponds to the term mountain fog as described by Bruijnzeel et al. (2005). A comparative study showed that in winter (August) $90 \%$ of the fog over land is of advective origin, while $10 \%$ is orographic. The situation changes in summer (January) when there is less fog and orographic events are more frequent than advective events (Farías et al., 2005). Generally, orographic fog develops at the coastal cliff and radiation fog occurs further inland (Cereceda et al., 2002).

A land-sea breeze system is dominant at the site (Schwerdtfeger, 1976), causing the winds from the ocean during the day. After an abrupt change of the direction in the evening, the wind blows from the land to the ocean during the night.

To measure the physical characteristics of the fog and fog deposition to the surface, instrumentation was installed in the center sector (13 ha) of the 31-ha-Tillandsia carpet at Cerro Guanaco. The 10 to $20 \mathrm{~cm}$ high plants grow on the western slopes of extended hilly sandy bands that are oriented in the $\mathrm{N}$-S direction. These 0.3 to $1.8 \mathrm{~m}$ high and 0.5 to $12.0 \mathrm{~m}$ wide bands seem like small dunes. The Tillandsia carpet covers up to $42 \%$ of the surface, with the eastern slopes of the hills being bare land. The bulk of the terrain slopes toward the west with a $4^{\circ}$ inclination (Cereceda et al., 2007).

On top of a hill in the center sector, a $4 \mathrm{~m}$ high scaffold with an optical fog droplet spectrometer (FM-100,
Droplet Measurement Technologies Inc.) and an ultrasonic anemometer (YOUNG 81000, R. M. Young) was installed.

With the spectrometer, which was oriented into the main wind direction, number and sizes of droplets ranging from 2 to $50 \mu \mathrm{m}$ diameters were measured with a sampling frequency of $10 \mathrm{~Hz}$ and in 40 size classes. Liquid water content (LWC) was derived using the air flow rate through the sample area and the droplet number concentrations. The three-dimensional wind was measured with the ultrasonic anemometer at a sampling rate of $10 \mathrm{~Hz}$.

To obtain the total vertical fog water flux between surface and atmosphere $D_{\text {total }}\left[\mathrm{g} \mathrm{m}^{-2} \mathrm{~s}^{-1}\right]$, gravitational and turbulent flux were calculated and summed by:

$D_{\text {total }}=D_{\text {sed }}+D_{\text {turb }}$

$D_{\text {sed }}$ was determined using Stoke's sedimentation velocity $\left(v_{s}\right)$ (Beswick et al., 1991) according to

$v_{s}=\frac{g d^{2}\left(\rho_{\mathrm{water}}-\rho_{\mathrm{air}}\right)}{18 \eta_{\text {air }}}$

where $g$ is the acceleration due to gravity $\left[\mathrm{m} \mathrm{s}^{-2}\right], \eta$ is the dynamic viscosity $\left[\mathrm{kg} \mathrm{m}^{-1} \mathrm{~s}^{-1}\right], d$ is the droplet diameter $[\mathrm{m}]$ and $\rho$ is the density of air $\left[\mathrm{kg} \mathrm{m}^{-3}\right]$. The sedimentation velocity $v_{s}\left[\mathrm{~m} \mathrm{~s}^{-1}\right]$, calculated for every class $i$, was multiplied by the $\mathrm{LWC}_{i}\left[\mathrm{~g} \mathrm{~m}^{-3}\right]$ to obtain the gravitational contribution $D_{\text {sed }}\left[\mathrm{g} \mathrm{m}^{-2} \mathrm{~s}^{-1}\right]$ to the fog water deposition:

$D_{\text {sed }}=\sum_{i} v_{s, i} \cdot \mathrm{LWC}_{i}$

$D_{\text {turb }}$ depends on the turbulent exchange between surface and atmosphere. Air parcels and scalars such as momentum, heat, gases, and water droplets, are subject to turbulent transport through eddies.

To determine the turbulent flux in the vertical direction, the covariance of two time series, the vertical wind and the scalar c (e.g. LWC), was calculated by:

$F_{c}=\overline{w^{\prime} \cdot c^{\prime}}$

$F_{c}$ is the vertical flux of the scalar $c$ and $w$ is the vertical wind. The overbar indicates a temporal average, in this case for $30 \mathrm{~min}$, as is widely applied in eddy covariance flux measurements. The primes signify that the deviation of the component from its temporal mean is used, e.g. $w^{\prime}=w-\bar{w}$. It is furthermore defined that $\overline{w^{\prime}}=0$ and $\overline{c^{\prime}}=0$.

Gravitational settling is important for droplets with diameters $>10 \mu \mathrm{m}$, whereas turbulent deposition is especially efficient for small droplets which can better follow the air motion. The relative importance of each process depends on the droplet size distribution and the intensity of turbulent mixing (Burkard et al., 2003).

During data processing the double rotation method was used to align the horizontal wind component $(u)$ with the mean wind and to obtain a zero average for the other wind 
components $v$ and $w$ (Foken, 2008). Additionally, stationarity of the scalar measurements was tested by calculating the variance of 5-min intervals for every size class and compare them to the variance of the 30-min interval. If the deviation was higher than 50\%, linear detrending was applied (Foken and Wichura, 1996). Finally, the time series of the vertical wind speed and the scalar measurements were crosscorrelated to achieve optimum synchronization of these time series.

\section{Results}

Measurements were realized between 31 July and 19 August 2008 , during which fog occurred $16 \%$ of the time. Of the $66 \mathrm{~h}$ of data collected in foggy conditions, $21 \mathrm{~h}$ passed the quality check and were used for further analysis. One quality criterion was wind direction. The spectrometer was oriented toward the southwest $\left(215^{\circ}\right)$ into the main wind from the ocean for isoaxial sampling. Hours during which the wind differed more than $30^{\circ}$ from that direction were excluded because the spectrometer discriminates against large droplets not directly approaching the inlet. As much as $42 \mathrm{~h}$ had to be eliminated for this criterion since fog often occurred during evenings and nights when the wind changed direction. It is assumed that the usable times when fog originated from the ocean are much more important for Tillandsia landbecki than the times when fog originated over land. The carpets exclusively occur on the slopes oriented toward the ocean to collect fog water originating from this direction.

An important requirement for successful application of the eddy covariance method is the presence of a sufficiently developed turbulence regime. The friction velocity $\left(u^{*}\right)$ is often used as a quality criterion. Data with $u^{*}<0.1 \mathrm{~m} \mathrm{~s}^{-1}$ were therefore rejected $(3 \mathrm{~h})$. Also a few values for the LWC for discrete size classes were not used because they did not comply with the stationarity criterion after linear detrending.

The mean LWC of the $21 \mathrm{~h}$ passing quality control tests was calculated to be $347 \mathrm{mg} \mathrm{m}^{-3}$ and the mean total flux $D_{\text {total }}$ was $-10 \mathrm{mg} \mathrm{m}^{-2} \mathrm{~s}^{-1}$, the negative sign indicating downward flux (deposition). About $2.5 \mathrm{~L}$ of water were estimated to be deposited per $\mathrm{m}^{2}$ during the measuring period from 31 July to 19 August 2008, 40\% being of turbulent nature, and $60 \%$ due to gravitational deposition. This estimate is based on the assumption that the measured downward flux is identical to the deposition flux at the surface. Potential limitations of the validity of this assumption are discussed in Sect. 4 below. With the same reasoning, the mean total flux was furthermore applied to estimate the amount of water deposited during August 2008 and for a whole year. Based on a probability of fog of $16 \%$ for the month of August, a total downward flux of $4.4 \mathrm{~L} \mathrm{~m}^{-2}$ was derived. To roughly estimate the deposition for a whole year, data of passive standard fog collectors (SFC) at Cerro Guanaco were employed. In 2006 and 2007, the amount of collected water was quanti-

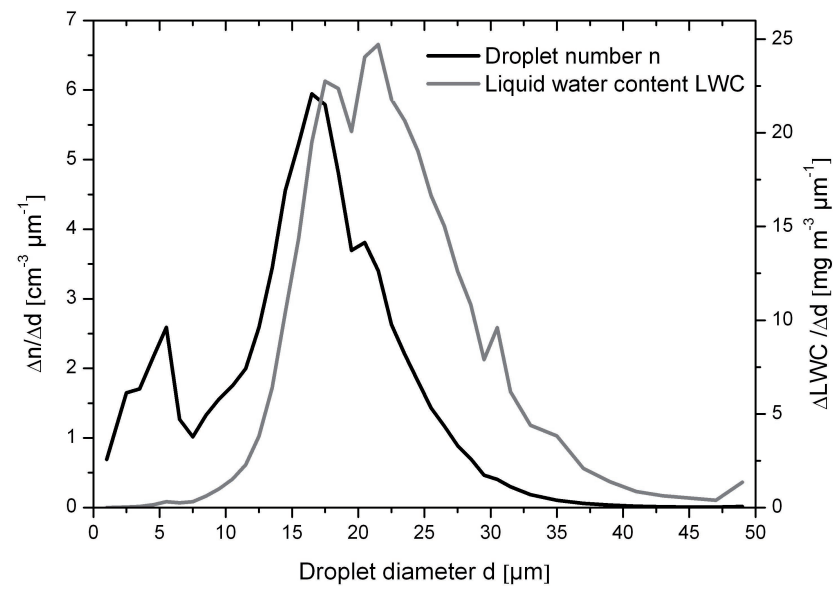

Fig. 1. Size distribution of the mean droplet number and the mean LWC for 11, 17 and 18 August 2008.

fied every month. Since the SFCs were built at a height of $2 \mathrm{~m}$ above ground, and were directed into the wind with a mesh of very good collection properties, the SFCs remove more water from the air than Tillandsia. Nevertheless, the amounts of collected fog water during each month and compared to the August 2008 data can be used to derive an estimate of fog water deposition over the year. The monthly fluxes measured with the SFCs during 2006 and 2007 were averaged and their proportion of the annual flux was calculated. Since during the measuring period in August the probability for fog was $16 \%$, probabilities for the other months were derived depending on the proportion of the collected amount of water in comparison to August. With those probabilities, the hours with fog for every month could be estimated and multiplied with the mean flux of the measuring period in August 2008. Based on these data, the amount of water depositing during one year was estimated to be $25 \mathrm{~L} \mathrm{~m}^{-2}$. The uncertainty of this estimate is unknown. Nevertheless, Garreaud et al. (2008) found a high positive correlation $(r=0.81)$ between the number of foggy days per month and the amount of water collected by SFCs further south at the coast of Chile $\left(30^{\circ} \mathrm{S}\right)$ in 1989 and 1990.

The data which passed quality control $(21 \mathrm{~h})$ were collected during three days with uninterrupted fog conditions of over several hours in duration each. The respective fog events started in the afternoons of 11, 17 and 18 August 2008 and lasted until the next mornings. In Figs. 1-3 the data for these days are shown until the times when the wind direction changed due to the shift of the land-sea breeze system.

For the droplet number concentration of fog droplets averaged over the three days, a bimodal distribution was found (Fig. 1). The first peak at about $5 \mu \mathrm{m}$ reveals no significant influence on the LWC and has only been detected for the initial stages of the fog events on 17 and 18 August 2008. When the event started, the edge and upper section of the 




Fig. 2. Temporal evolution of the turbulent fog water flux (lower panel) and the corresponding sensible heat flux (upper panel) for the 3 fog events. The dashed area indicates local sunset.

Sc cloud passed the experimental setup. At the cloud edge, more dynamic processes occur than in the center of the cloud. Droplets may rapidly deliquesce, or dry air parcels may be entrained.

The largest contribution to the LWC originates from medium size droplets of diameters between 15 and $30 \mu \mathrm{m}$. These droplets also have the strongest impact on the turbulent fog water flux (Fig. 3).

On all three days, the turbulent flux of fog water was first directed toward the ground for several hours. Shortly before the wind changed its direction, upward fluxes were observed (Fig. 2). Those upward fluxes occurred at different times of the day: on 11 August 2008, the turbulent flux turned positive relatively early at about 17:00 local time (LT,UTC -04:00), whereas on 17 August 2008 upward fluxes started at 19:30 LT, and on 18 August 2008 at 22:00 LT. Before the wind turned, its direction was very stable. The horizontal wind velocity decreased during the events and reached a magnitude of about 3 to $4 \mathrm{~m} \mathrm{~s}^{-1}$ during emissions.

At those times when the turbulent fog water fluxes turned positive, the sensible heat flux decreased rapidly (Fig. 2). Its

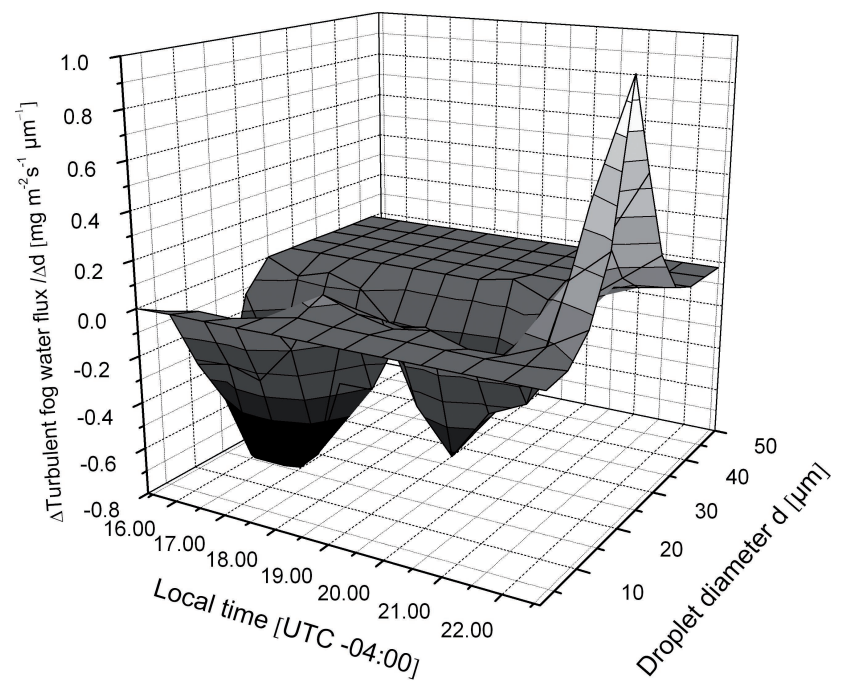

Fig. 3. Turbulent fog water flux adjusted to the different size ranges of the spectrometer ( $\Delta$ Turbulent fog water flux/ $\Delta$ d) over droplet diameter and time for 18 August 2008. 30-min intervals are shown as obtained with the eddy covariance method.

trend indicates a (negative) correlation with the turbulent fog water flux. A negative sensible heat flux implies turbulent transport of sensible heat toward the ground. Upward fluxes of fog droplets occurred only when the sensible heat fluxes were strongly negative.

The medium size droplets $(15-25 \mu \mathrm{m})$ that were predominantly contributing to the LWC, also greatly influenced the turbulent fog water flux (during deposition and emission). This is valid for all three days and can be seen for $18 \mathrm{Au}-$ gust 2008 in Fig. 3. Droplets smaller than $15 \mu \mathrm{m}$ were also emitted, but could not affect the turbulent LWC flux as they contain little water.

\section{Discussion}

This is the first application of the eddy covariance method to measure the deposition flux of fog water to a desert environment. Despite the extremely arid conditions with about $0.8 \mathrm{~mm}$ of rain per year over the past 30 years at Cerro Guanaco, where the Atacama desert meets the Pacific ocean, a healthy and stable Tillandsia landbecki carpet persists. The only apparent reliable freshwater source is the deposition of fog water and dew. From our experiments we estimate the fog deposition during August 2008 to have been about $4.4 \mathrm{~L} \mathrm{~m}^{-2}$. For a one-year period, about $25 \mathrm{~L} \mathrm{~m}^{-2}$ are probably available for Tillandsia landbecki from fog.

These amounts of water are a first bulk estimate of the deposition flux. Uncertainties for this estimate are two-fold. First, a small amount of data was used to extrapolate to a yearly flux. To significantly increase the quality of the 
estimate, a much larger data set needs to be collected which covers many more fog events during various seasons of the year. Secondly, an underestimation of the surface fluxes of fog water may result from vertical flux divergences. Kowalski and Vong (1999) found a vertical flux divergence between two measuring heights at a hilltop over a Douglas fir forest (USA). They proposed that similar divergences could occur at other hillslope locations and should be taken into account to avoid underestimation of fog deposition at the canopy level.

Analogous results were found by Holwerda et al. (2006) for a Puerto Rican elfin cloud forest. They estimated fog deposition by the eddy covariance method and by quantifying the water budget. Comparison of the two methods indicated an underestimation of the flux at canopy level by the eddy covariance method which does not allow the determination of the flux at canopy level defined as gross flux by Eugster et al. (2006), but can only be used to determine the smaller net flux. The discrepancy between gross and net flux was explained by condensation and concurrently occurring deposition to the vegetation in air moving upslope ( $17^{\circ}$ slope). Both Kowalski and Vong (1999) and Holwerda et al. (2006) measured over complex terrain with much steeper slopes, and over forests. Although there is a theoretical chance that the proposed processes may have occurred at our site as well, we believe that it is a different process that led to the measured upward fluxes at the Atacama Desert site.

We observed positive (upward) fog water fluxes on three days of good data quality. These upward fluxes occurred at different times during each evening. Under stationary conditions, such upward fluxes can occur only when there is a source for LWC between the height of the measurement setup and the surface. A possible explanation for these positive fog water fluxes is the formation of radiation fog. The sensible heat flux is oriented downward, toward the surface, during the periods of upward fluxes of fog water. Presumably the desert soils cool quickly once incoming shortwave radiation stops, due to the occurrence of fog or due to the beginning of the night. Heat transfer to the ground leads to cooling of near-surface air, fostering condensation. There is an indication that the soil was cooled when the upward fluxes occurred. The formation of the land-sea breeze is driven by temperature differences between land and ocean. Shortly before the wind turns (then originating from the land) positive fluxes occur. Therefore the land surface could have been on the verge of being cooler than the ocean. The soil temperature would have decreased, being able to cool air layers at ground level.

The upward fog water flux does not occur at the same time every day, but likely depends on duration of the current fog event. On 11 August 2008 the upward flux started at about 17:00 LT, several hours earlier than on the other two days (17 August 2008: 19:30 LT, and 18 August 2008: 22:00 LT). If fog starts at midday, for example on 11 August 2008, little radiation had yet reached the ground. The land-cooling be- gan earlier than on days that fog started in the afternoon over a warmer land surface. Therefore the formation of radiation fog began earlier as well.

If our explanation is correct and additional radiation fog developed during the fog events, there was a source of liquid water between the surface and the measuring height. Under these conditions, the fog water flux may have been directed both downward at the surface and, at the same time, upward at the measurement setup. This indicates the possibility of additional deposition that was undetected by the instruments. The turbulent flux toward the vegetation may thus be underestimated by our setup.

In addition to the water the Tillandsias collect from the fog, Tillandsias can also use dew as a water source. It is not known how frequent dew occurs and how much more water the plants obtain from this source. This could be an object for future research.

To make more precise estimations of the amount of depositing fog water and to validate the hypothesis that radiation fog occurs during advective fog events at Cerro Guanaco, further experiments are urgently required. These should include the quantification of energy balance terms in order to study the driving processes in more detail. Also, alternative methods to determine the amount of depositing fog water should be applied.

Acknowledgements. We thank the German Academic Exchange Service (DAAD) for supporting this research through a travel fund, Pablo Vidal for help during field work, and Luke D. Ziemba for language-editing of the manuscript.

Topical Editor F. D'Andrea thanks W. Eugster and another anonymous referee for their help in evaluating this paper.

\section{References}

Beiderwieden, E., Schmidt, A., Hsia, Y.-J., Chang, S.-C., Wrzesinsky, T., and Klemm, O.: Nutrient Input through Occult and Wet Deposition into a Subtropical Montane Cloud Forest, Water Air Soil Poll., 186, 273-288, 2007.

Beiderwieden, E., Wolff, V., Hsia, Y.-J., and Klemm, O.: It goes both ways: measurements of simultaneous evapotranspiration and fog droplet deposition at a montane cloud forest, Hydrol. Processes, 22, 4181-4189, 2008.

Beswick, K. M., Hargreaves, K. J., Gallagher, M. W., Choularton, T. W., and Fowler, D.: Size-resolved measurements of cloud droplet deposition velocity to a forest canopy using an eddy correlation technique, Q. J. Roy. Meteorol. Soc., 117, 623-645, 1991.

Bruijnzeel, L. A., Eugster, W., and Burkard, R.: Fog as in hydrological input, in: Encyclopedia of Hydrological Sciences, John Wiley \& Sons, New York, 559-582, 2005.

Burkard, R., Bützberger, P., and Eugster, W.: Vertical fog water flux measurements above an elevated forest canopy at the Lägeren research site, Switzerland, Atmos. Environ., 37, 2979-2990, 2003.

Cereceda, P., Larrain, H., Osses, P., Farías, M., and Egaña, I.: The climate of the coast and fog zone in the Tarapaca Region, Atacama Desert, Chile, Atmos. Res., 87, 301-311, 2008. 
Cereceda, P., Osses, P., Larrain, H., Farías, M., Lagos, M., Pinto, R., and Schemenauer, R. S.: Advective, orographic and radiation fog in the Tarapaca region, Chile, Atmos. Res., 64, 261-271, 2002.

Cereceda, P., Osses, P., Larrain, H., and Pérez, L.: Biogeographical and phytosociological characteristics of the Tillandsia fields at the fog oasis of Cerro Guanaco, Tarapaca, Chile, Fourth International Conference on fog collection and dew, La Serena, Chile, 22-27 July 2007, 177-180, 2007.

del-Val, E., Armesto, J. J., Barbosa, O., Christie, D. A., Gutirrez, A. G., Jones, C. G., Marquet, P. A., and Weathers, K. C.: Rain forest islands in the chilean semiarid region: Fog-dependency, ecosystem persistence and tree regeneration, Ecosystems, 9, 598-608, 2006.

Eugster, W., Burkard, R., Holwerda, F., Scatena, F. N., and Bruijnzeel, L. A. S.: Characteristics of fog and fogwater fluxes in a Puerto Rican elfin cloud forest, Agr. Forest Meteorol., 139, 288306, 2006.

Farías, M., Osses, P., Cereceda, P., and Larrain, H.: Comportamiento espacio-temporal de la nube estratocúmulo, productora de niebla en la costa del desierto de Atacama ( $21^{\circ}$ lat. S., $70^{\circ}$ long. W.), durante un mes de invierno y otro de verano, Investigaciones Geográficas, 56, 43-67, 2005.

Foken, T.: Micrometeorology. Springer-Verlag Berlin Heidelberg, Germany, 2008.

Foken, T. and Wichura, B.: Tools for quality assessment of surfacebased flux measurements, Agr. Forest. Meteorol., 78, 83-105, 1996.

Gallagher, M. W., Beswick, K., and Choularton, T. W.: Measurements and Modelling of Cloudwater Deposition to Moorland and Forests, Environ. Pollut., 75, 97-107, 1992.

Garreaud, R. D., Christie, D., Barichivich, J., and Maldonado, A.: The Climate and Weather of the West Coast of Subtropical South America, Fourth International Conference on fog collection and dew, La Serena, Chile, 22-27 July 2007, 21-24, 2007.

Garreaud, R. D., Barichivich, J., Christie, D., and Maldonado, A.: Interannual variability of the coastal fog at Fray Jorge relict forest in semiarid Chile, J. Geophys. Res., 113, G04011, doi:10.1029/2008JG000709, 2008.
Holwerda, F., Burkard, R., Eugster, W., Scatena, F. N., Meesters, A. G. C. A., and Bruijnzeel, L. A.: Estimating fog deposition at a Puerto Rican elfin cloud forest site: comparison of the water budget and eddy covariance methods, Hydrol. Processes, 20, 2669-2692, 2006.

Klemm, O. and Wrzesinsky, T.: Fog deposition fluxes of water and ions to a mountainous site in Central Europe, Tellus B, 59, 705714, 2007.

Klemm, O., Wrzesinsky, T., and Scheer, C.: Fog water flux at a canopy top: Direct measurement versus one-dimensional model, Atmos. Environ., 39, 5375-5386, 2005.

Kowalski, A. S. and Vong, R. J.: Near-surface fluxes of cloud water evolve vertically, Q. J. Roy. Meteorol. Soc., 125, 2663-2684, 1999.

Peel, M. C., Finlayson, B. L., and McMahon, T. A.: Updated world map of the Köppen-Geiger climate classification, Hydrol. Earth Syst. Sci., 11, 1633-1644, 2007, http://www.hydrol-earth-syst-sci.net/11/1633/2007/.

Rundel, P., Palma, B., Dillon, M., Sharifi, M., Nilsen, E., and Boonpragob, K.: Tillandsia landbeckii in the Coastal Atacama Desert of Northern Chile, Rev. Chil. Hist. Nat., 70, 341-349, 1997.

Schwerdtfeger, W.: World Survey of Climatology Volume 12 - Climates of Central and South America, Elsevier Scientific Publishing Company, Amsterdam, Netherlands, 1976.

Thalmann, E., Burkard, R., Wrzesinsky, T., Eugster, W., and Klemm, O.: Ion fluxes from fog and rain to an agricultural and a forest ecosystem in Europe, Atmos. Res., 64, 147-158, 2002.

Vermeulen, A. T., Wyers, G. P., Romer, F. G., VanLeeuwen, N. F. M., Draaijers, G. P. J., and Erisman, J. W.: Fog deposition on a coniferous forest in The Netherlands, Atmos. Environ., 31, 375386, 1997.

Vong, R. J. and Kowalski, A. S.: Eddy correlation measurements of size-dependent cloud droplet turbulent fluxes to complex terrain, Tellus B, 47, 331-352, 1995. 